\title{
Extracción y caracterización de pectinas obtenidas a partir de frutos de la biodiversidad peruana
}

Nancy Chasquibol Silva, Edmundo Arroyo Benites, Juan Carlos Morales Gomero*

Ingeniería Industrial n. 26, 2008, ISSN 1025-9929, pp. 175-199

Resumen: Se determinó el análisis de pectina en varias especies frutales de la biodiversidad peruana de origen costeño, andino y amazónico. La extracción y caracterización de las pectinas se realizó en los frutos del níspero de la sierra (Nespilus germánica) y de la granadilla (Pasiflora ligularis), que destacaron por su alto contenido de ácido galacturónico (87,97\% y 85,99\%), alto grado de metoxilación (89,15\% y 88,24\%), alto grado de esterificación (86,24\% y 88,79\%), comprobado por espectrofotometría FT-IR, y alto peso molecular (10183,5 y 16366,96), respectivamente. Este proyecto de investigación ha sido desarrollado en el laboratorio de docimasia de la Facultad de Ingeniería Industrial de la Universidad de Lima y cuenta con la aprobación oficial del Instituto de Investigación Científica (IDIC).

Palabras clave: Biodiversidad, pectina, extracción, caracterización

\section{Extraction and characterization of pectins in several types of fruits of the peruvian biodiversity}

Abstract: The pectin content was determinated in several types of fruits from the Peruvian biodiversity and the extraction and characterization of pectins were carried out in the fruits of níspero de la sierra (Nespilus germánica) and granadilla (Pasiflora ligularis); both fruits contained high amount of galacturonic acid (87,97\% and 85,99\%), high degree of metoxilation (89,15\% and $88,24 \%)$, high degree of sterification (86,24\% and $88,79 \%)$, and high molecular weight (10183,5 and 16366,96), respectively. This research project was carried out in the laboratory of Docimasia of the Industrial Engineering Faculty of the Universidad de Lima and it was approved by The Institute of Scientific Investigation.

Keywords: Biodiversity, pectin, extraction, characteristic

* Los autores agradecen al personal del laboratorio de Docimasia de la Universidad de Lima, que colaboró en la realización de este trabajo. 


\section{INTRODUCCIÓN}

En los últimos años los productos bionaturales han cobrado importancia debido a sus inunmerables beneficios para la salud. Uno de estos productos es la pectina, que es un biopolímero constituido principalmente por ácido galacturónico, y que gracias a sus propiedades gelificantes y de absorción se emplea en la industria de los alimentos, cosmética y farmacéutica.

La pectina es una sustancia natural que se forma principalmente en la pared primaria y en los tejidos mesenquimáticos y parenquimáticos de frutos y vegetales, y tiene la función de cemento intercelular (Nwanekesi, Alawuba y Mkpolulu, 1994:159-161; Srinrangarajan, y Shrikhande, 1979: 567-569)

La pectina fue aislada por primera vez por el químico francés Henri Braconnot en 1825, quien la designó como "pectina", que deriva del griego pektikos, que significa congelar o solidificar (Willats, Knox, Dalgaard, 2006: 97-104).

La pectina forma coloides por excelencia, ya que tiene la propiedad de absorber una gran cantidad de agua, pertenecen a la familia de los oligosacáridos y polisacáridos de alto peso molecular y contienen largas cadenas formadas por unidades de 1,4- $\alpha$-D-ácido galacturónico (GalpA). Tres polisacáridos pécticos (homogalacturona, rhamnogalacturona-I y galacturonas sustituidas) han sido separados y caracterizados y todos contienen GalpA en mayor o menor cantidad. Hasta hace poco se ha aceptado que los polisacáridos homogalacturona y rhamnogalacturona-I son los constituyentes principales de los polímeros pécticos, como se muestra en la figura 1a. Sin embargo, en una estructura alternativa, propuesta recientemente, el polisacárido homogalacturona es una larga cadena de rhamnogalacturona-I (figura 1b) (Willats, Knox, Dalgaard, 2006: 97-104). 


\section{Figura 1}

Estructura básica de la pectina: (a) Representación esquemática convencional; (b) Representación nueva

a)

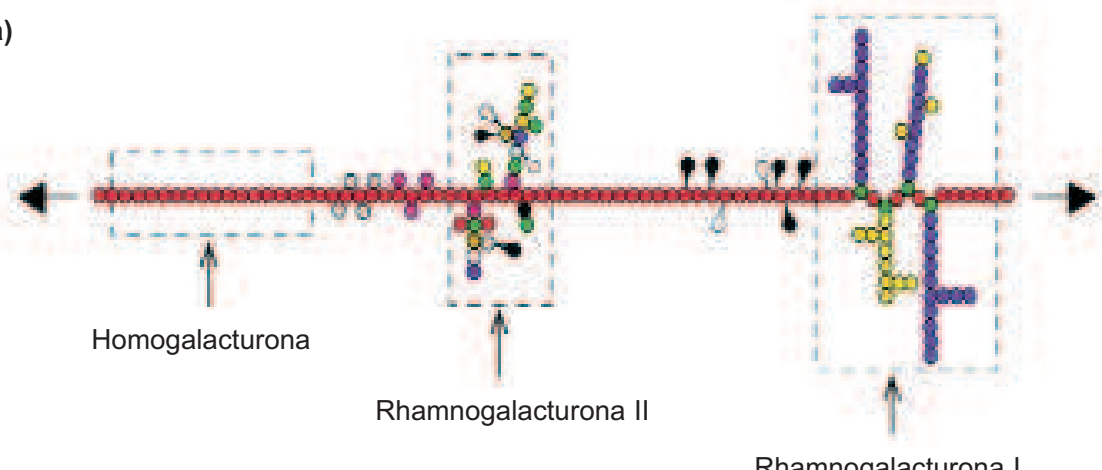

Rhamnogalacturona I

b)

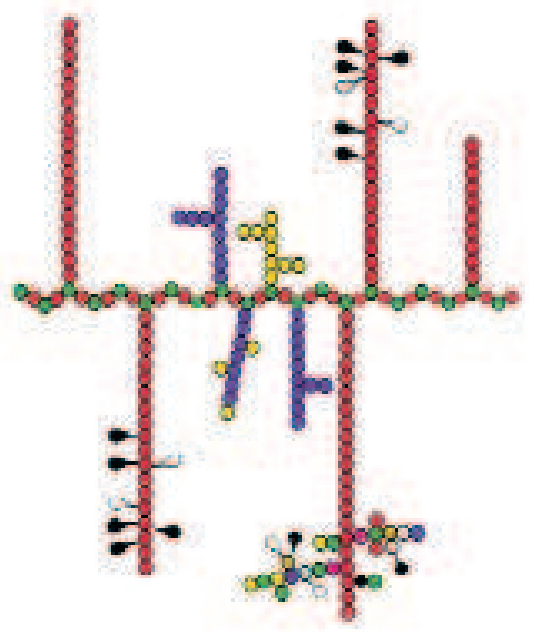

Q Ester acetílico 1 Ester etílico

- Ácido galacturónico (GalA)

e Rhamnosa (Rha)

- Apiosa (Api)

c. Fucosa (Fuc)

0. Ácido acérico (AceA)

- Galactosa (Gal)

Q Arabinosa (Ara)

o Xylosa (Xyl)

Q Ácido glucorónico (GIcA)

- Ácido cetodioximanno-octulopiranosilónico (CDO)

* Ácido heptulopiranosilárico (Dha) acid (Dha)

Ácido deoxilixo 
La homogalacturona (HG) (figura 2) es una cadena lineal de 1,4- $\alpha$ D-ácido galactorónico (AgalD), en el cual algunos de los grupos carboxilos están metil esterificados (Ridley, O’Neill, Mohnen, 2001: 929-967).

Figura 2

Estructura primaria del polímero lineal homogalacturona unido con 1,4- $\alpha$-D-ácido galacturónico (GalpA)

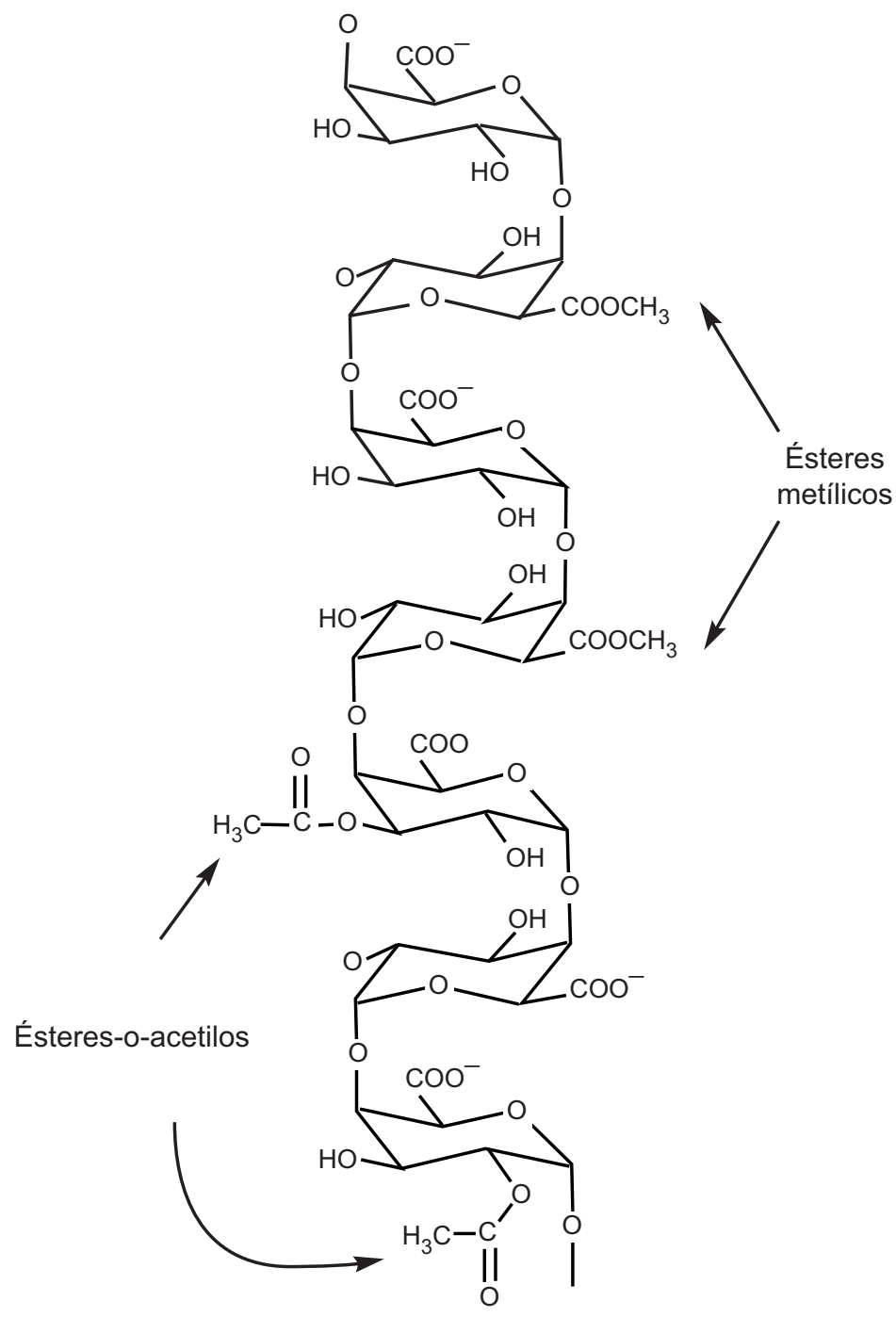


Figura 3

Estructura principal del polisacárido péptico de la rhamnogalacturona-I (RG-I)

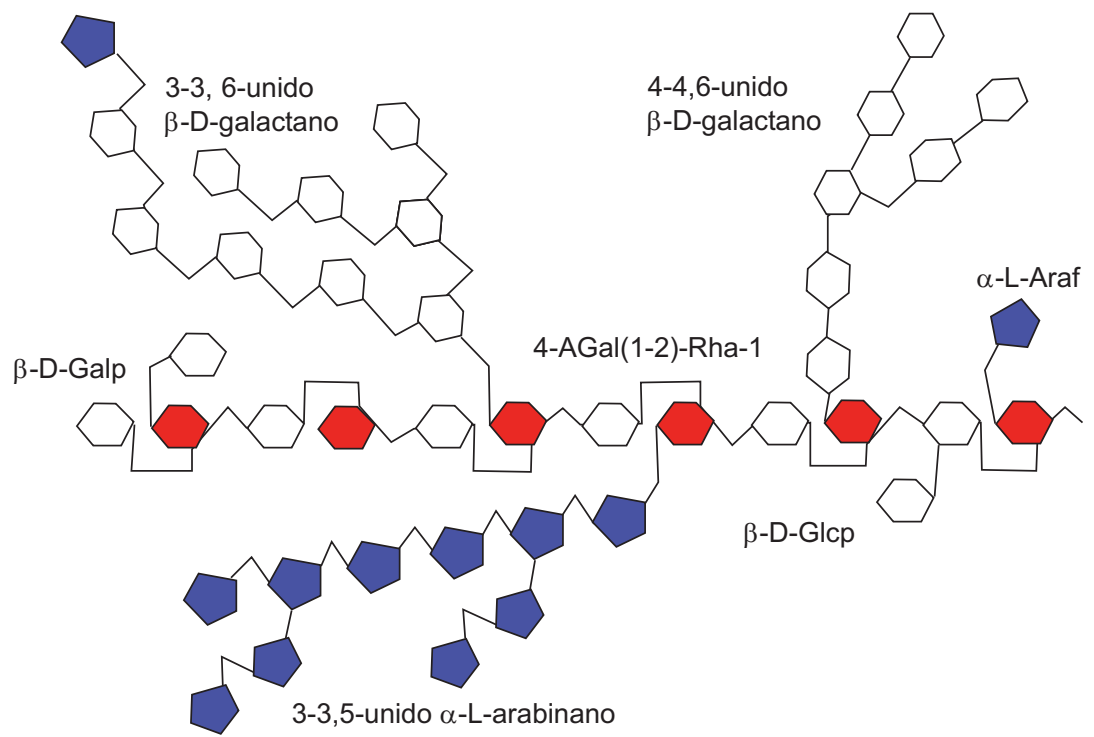

La rhamnogalacturona-I (RG-I) (figura 3) es una familia de polisacáridos pépticos que contienen disacáridos con unidades repetidas de $[\rightarrow 4-\alpha-$ D-AGAL- $(\rightarrow 2)-\alpha-$ L-Rhamnosil(Rhap) $-(1 \rightarrow]$.

Los oligosacáridos lineales y ramificados están compuestos predominantemente de $\alpha$-L-Arabinofuranosil (Araf) y $\beta$-D-Galactopiranosil (AGAL) y están unidos al $\mathrm{C} 4$ de algunos de los residuos de ramnosil (Ridley, O’Neill, Mohnen, 2001: 929-967).

La rhamnogalacturona-II (RG-II) es un polisacárido que contiene en su estructura lineal residuos de $\alpha$-D-ácido galacturónico (AGAL). Este polisacárido está presente en las paredes celulares de las plantas (O’Neil, Albersheim, Darvill, 1990: 445-491).

La demostración de que el vino y otros jugos de frutas contienen cantidades relativamente altas de RG-II (20-150 mg) (Doco, Williams, Vidal, Pellerin, 1997:181-186), que la RG-II está enlazada con metales pesados (Pellerin, O'Neil, Pierre, Darvill, Albersheim, Moutormet, 
1997: 33-41; Pellerin, O’Neil, 1998: 26, M32-M36; Szpubar, Pellerin, Makov, Doco, Willianm, Lobinski, 1999: 639-644; Tahiri, Pellerin, Tressol, Doco, Pepin, Rayssignior, Coudray, 2000: 149-253) y que la RG-II tiene actividades inmunológicas (Shin, Kihyohara, Matsumoto, Yamada, 1998: 97-106) ha incrementado el interés en la estructura de este polisacárido, así como su rol en nutrición y salud humana.

En las frutas, la mayoría de los grupos ácidos del ácido galacturónico están esterificados por metanol. Este metanol puede perderse con relativa facilidad por hidrólisis ácida o enzimática, dejando el grupo ácido libre. En función del porcentaje de restos de ácido galacturónico esterificado las pectinas se clasifican como de alto metoxilo cuando este porcentaje es superior al $65 \%$ y de bajo metoxilo cuando es inferior.

Para fines industriales, las fuentes de obtención de las pectinas se restringe principalmente a las cáscaras de los frutos cítricos (20-35\%), infrutescencia del girasol (15-25\%), remolacha (10-20\%) y pulpa de manzana (10-15\%).

La pectina es ampliamente usada como ingrediente funcional en la industria de los alimentos y como fuente de fibra dietética, debido a su habilidad para formar geles acuosos. Los geles de pectina son importantes para crear o modificar la textura de compotas, jaleas, salsas, kétchup, mayonesas, confites; en la industria láctea para la fabricación de yogures frutados y productos lácteos bajos en grasa, en la industria de bebidas dietéticas para la preparación de refrescos, debido a su bajo contenido de carbohidratos, por sus propiedades estabilizantes y por incrementar la viscosidad.

La pectina tiene efectos beneficiosos en la salud (Yamada, 1996: 173-190); por ello, tiene importantes aplicaciones en la industria farmacéutica y cosmética. Es empleada como ingrediente en preparaciones farmacéuticas como antidiarreicos, desintoxicantes y algunas drogas son encapsuladas con una película de pectina para proteger la mucosa gástrica y permitir que el componente activo se libere en la circulación de la sangre.

Las pectinas se emplean también como agentes absorbentes de lipoproteínas (productos farmacéuticos para bajar de peso) y últimamente se está investigando su aplicación como membranas biopoliméricas cicatrizantes. 
Además, la pectina reduce la intolerancia a la glucosa en diabéticos e incluso baja el nivel del colesterol sanguíneo y de la fracción lipoproteica de baja densidad; asimismo, ayuda en la inhibición potencial del cáncer y su metástasis (Heitman, Hardman y Cameron, 1992: 815818; Platt, Raz, 1992: 438-442; Nangia-Makker, Hogan, Honjo, Baccarini, Tait y Bresalier, 2002: 185418-62; Inohara y Raz, 1994: 527532; Pienta, Naik, Akhtar, Yamazaki, Replogle, Lehr, Donat, Tait, Hogan y Raz, 1995:348-353). Específicamente, se están realizando estudios sobre el efecto de los diferentes tipos de pectina en inhibir el crecimiento del cáncer a la próstata, así como también se están investigando y recomendando realizar cambios en la dieta basada en alimentos o productos nutracéuticos para combatir la incidencia del cáncer a la próstata, así como también de otros tipos de cáncer.

En la industria cosmética, la pectina es empleada en las formulaciones de pastas dentales, ungüentos, aceites, cremas, desodorantes, tónicos capilares, lociones de baño y champú, por sus propiedades suavizantes y estabilizantes.

También se le emplea en la producción de plásticos así como en la fabricación de productos espumantes, como agentes de clarificación y aglutinantes, y como material para la absorción de contaminantes de efluentes industriales líquidos; lo que demuestra el potencial y las aplicaciones futuras que se esperan de la pectina.

Se estima que la producción mundial de pectina es de 35.000 toneladas por año. Los principales productores son Dinamarca, Holanda, Estados Unidos, Canadá, México, Suiza y Alemania.

El Perú, al igual que la gran mayoría de los países de Latinoamérica, no produce pectina ni sus derivados, importándose para cubrir la demanda de la industria alimentaria y farmacéutica (cuadros 1 y 2). De esta región solo México ha logrado apropiarse del mercado mundial, exportando cerca de 5 mil toneladas al año, con un importe de 45 millones de dólares. El precio promedio de pectina dentro del país es de US\$11,97 (cuadro 3). 


\section{Cuadro 1 \\ Demanda de pectina en el Perú}

\begin{tabular}{cccc}
\hline Año & Importación $\mathbf{( k g )}$ & Exportación $\mathbf{( k g )}$ & Demanda $(\mathbf{k g})$ \\
\hline 2000 & $55.429,52$ & $1.900,00$ & $53.529,52$ \\
2001 & $52.710,00$ & 125,00 & $52.585,00$ \\
2002 & $74.640,03$ & 420,80 & $74.219,23$ \\
2003 & $80.345,00$ & 525,00 & $79.820,00$ \\
2004 & $119.651,05$ & $1.238,62$ & $118.412,43$ \\
2005 & $106.542,72$ & 475,00 & $106.067,72$ \\
2006 & $145.657,70$ & $1.100,00$ & $144.557,70$ \\
2007 & $117.733,74$ & $1.525,00$ & $116.208,74$ \\
& & & \\
& & Proyección estimada & \\
\hline 2008 & $167.084,88$ & $1.215,85$ & $165.869,02$ \\
2009 & $193.882,05$ & $2.315,48$ & $191.566,56$ \\
2010 & $211.491,52$ & $2.415,28$ & $209.076,24$ \\
2011 & $237.289,17$ & $2.903,36$ & $234.385,81$ \\
2012 & $258.950,25$ & $3.434,05$ & $255.516,20$ \\
2013 & $303.042,29$ & $4.997,14$ & $298.045,15$ \\
2014 & $338.852,88$ & $5.584,51$ & $333.268,38$ \\
2015 & $400.530,80$ & $6.920,33$ & $393.610,46$ \\
2016 & $435.787,23$ & $9.013,87$ & $426.773,36$ \\
2017 & $491.540,62$ & $10.509,24$ & $481.031,37$ \\
\hline
\end{tabular}

Fuente: Sunat.

Incluye pectinatos y pectatos.

\section{Cuadro 2}

Importación relativa de pectina por país de origen

\begin{tabular}{cccccc}
\hline Año & México (\%) & Dinamarca (\%) & Suecia (\%) & Francia (\%) & Otros (\%) \\
\hline 2000 & 24 & 45 & 18 & 7 & 6 \\
2001 & 36 & 28 & 10 & 15 & 11 \\
2002 & 56 & 12 & 8 & 14 & 10 \\
2003 & 54 & & 7 & 13 & 8 \\
2004 & 42 & 7 & 13 & 24 & 14 \\
2005 & 66 & 1 & 20 & 8 & 5 \\
2006 & 62 & 3 & 22 & 11 & 1 \\
2007 & 61 & 5 & 12 & 5 & 17 \\
\hline
\end{tabular}

Fuente: Reportes de la Sunat.

Incluye pectinatos y pectatos. 


\section{Cuadro 3 \\ Precio promedio de pectina en el Perú}

\begin{tabular}{cc}
\hline Año & $\begin{array}{c}\text { Precio importación } \\
\text { (US } \mathbf{/ k g})\end{array}$ \\
\hline 2000 & 12,10 \\
2001 & 12,21 \\
2002 & 11,58 \\
2003 & 12,77 \\
2004 & 12,29 \\
2005 & 12,30 \\
2006 & 11,46 \\
2007 & 11,03 \\
Promedio & 11,97 \\
\hline
\end{tabular}

Fuente: Reportes de la Sunat.

Incluye pectinatos y pectatos.

\section{PARTE EXPERIMENTAL}

Como materia prima para este trabajo se emplearon frutos nativos, oriundos de nuestro país, de origen amazónico, andino y costeño.

Se determinó el contenido total de pectina con $\mathrm{CaCl}_{2}$ en medio ácido (Gierselmer, 1997: 171-185) y el contenido de humedad, cenizas, proteínas, grasas, fibra y carbohidratos en los frutos con alto contenido de pectina total (AOAC, 1990).

\subsection{Proceso de obtención de la pectina}

El proceso de obtención de la pectina se realizó en tres etapas (diagrama 1).

\section{Diagrama 1 \\ proceso de obtención de peptina}

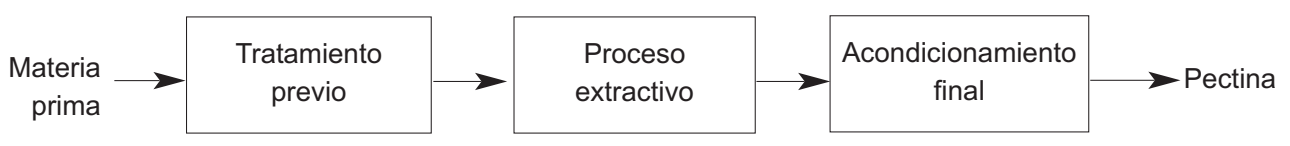




\subsection{Tratamiento previo}

La pulpa del níspero de la sierra y el mesocarpo blanco y esponjoso de la granadilla, seleccionados por su alto contenido de pectina total, fueron tratados previamente (diagrama 2); se cortaron en trozos pequeños y se colocaron en un recipiente de vidrio, con un litro de agua destilada, a una temperatura entre 85 y $95^{\circ} \mathrm{C}$ durante $15 \mathrm{minu}$ tos, con la finalidad de inactivar las enzimas pectinesterasas que hidrolizan los grupos de ésteres metílicos, formando metanol y pectinas de menor metoxilo; inactivando también la poligalacturonasa que rompe los enlaces glucosídicos entre moléculas galacturónicas, despolimerizando la cadena a fracciones más cortas y, finalmente, llegando al ácido galacturónico (Carbonell, Costell y Durán, 1990:1-9).

Mediante una tela de lienzo se separó el sólido del agua destilada, extrayendo la mayor cantidad de agua posible y lavando el sólido varias veces con agua destilada, para eliminar los azúcares y flavonoides. Este proceso se repitió por tres veces más.

Los sólidos de la pulpa del "níspero de la sierra" se dejaron en reposo por 24 horas en alcohol etílico para terminar de separar a los carotenoides y flavonoides. Finalmente, los sólidos de los frutos seleccionados se secaron a $60^{\circ} \mathrm{C}$ hasta alcanzar peso constante; se pesaron, pulverizaron y se envasaron herméticamente.

\subsection{Extracción de la pectina y acondicionamiento final}

El proceso de extracción y acondicionamiento final de la pectina de la pulpa del níspero de la sierra y del mesocarpo de la granadilla se realizó en varias etapas (diagrama 3). Se emplearon 25 gramos de muestra seca y molida, empleándose $\mathrm{HCl} 0.003 \mathrm{~N}$ (pH 2.5) como solución extractiva, en un sistema bajo reflujo con agitación constante, hasta alcanzar una temperatura de $90^{\circ} \mathrm{C}$ durante 75 minutos.

Luego se filtró en una tela de linillo, se exprimió manualmente y de inmediato se enfrió para minimizar la degradación por el calor. A la solución péctica se le agregó etanol al 98\% para precipitar la pectina, dejándola en reposo por una hora.

La pectina flotante fue filtrada, lavada con etanol de $95^{\circ}$ y secada a $40^{\circ} \mathrm{C}$ hasta obtener peso constante. El proceso global de la obtención de la pectina de la pulpa del níspero de la sierra y del mesocarpo de la granadilla se indica en el diagrama 4. 


\section{Diagrama 2}

Tratamiento previo de la pulpa del níspero de la sierra y del mesocarpio de la granadilla

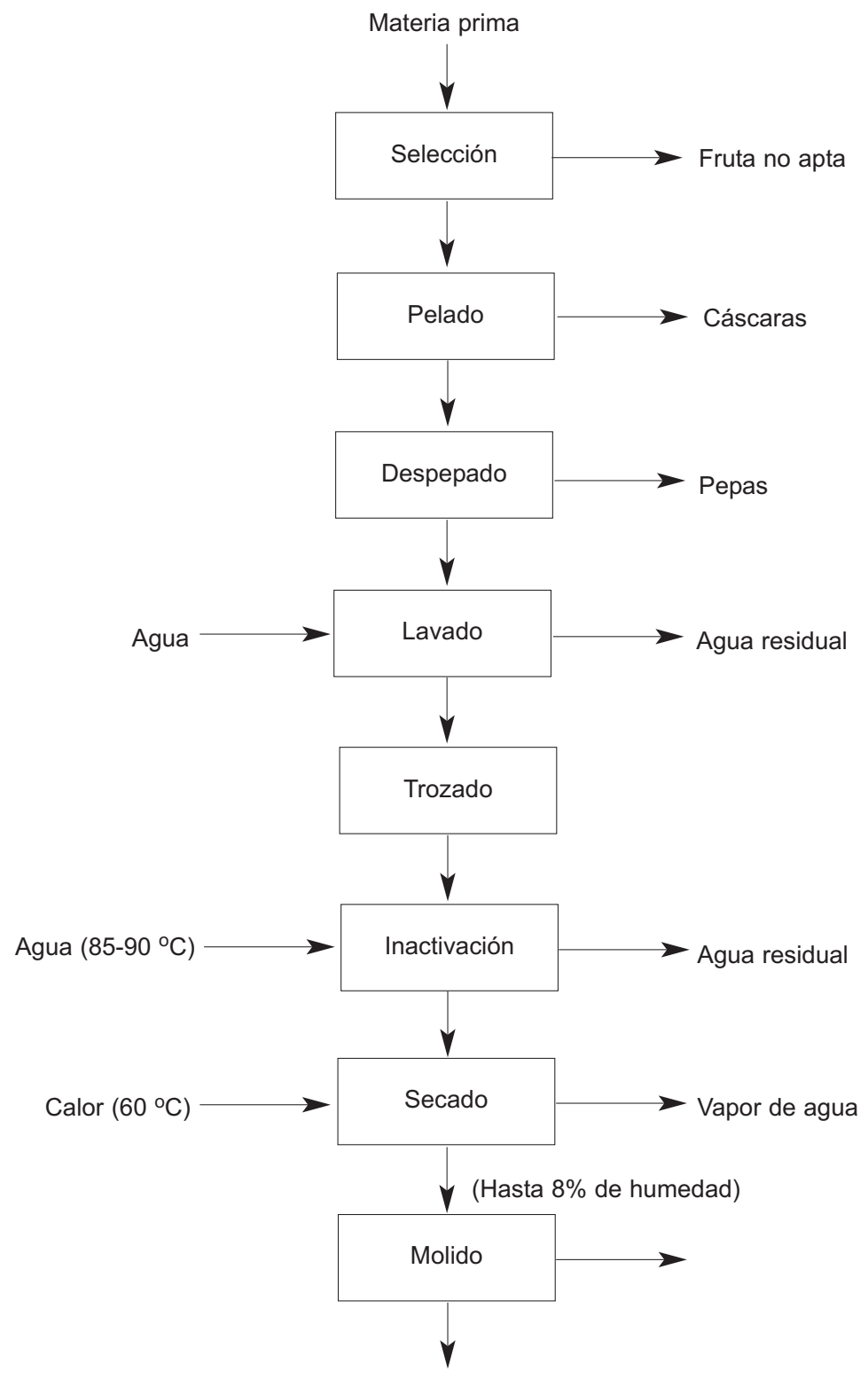


Diagrama 3

Extracción de la pectina y acondicionamiento final

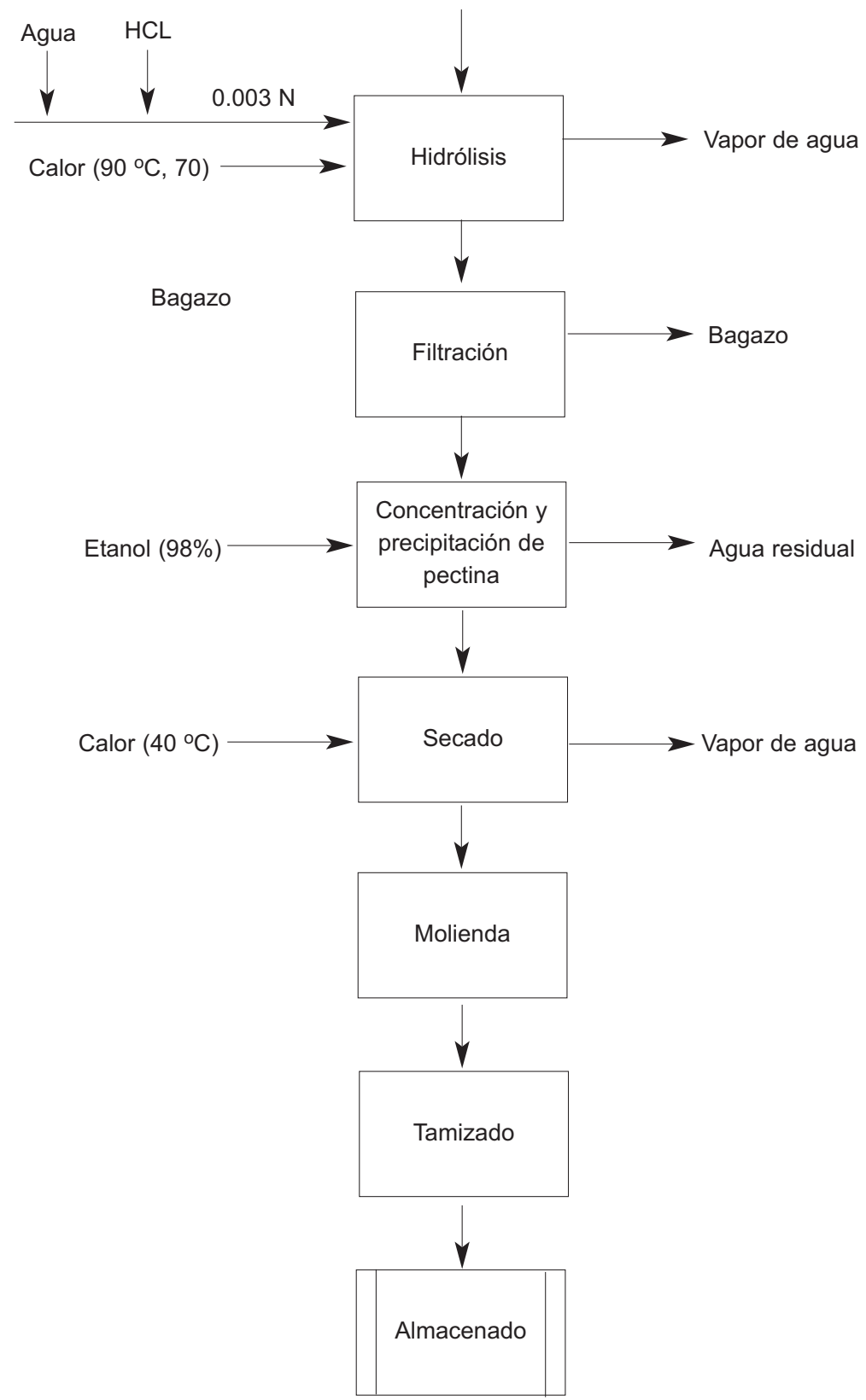




\section{Diagrama 4 \\ Proceso global de la obtención de pectina}

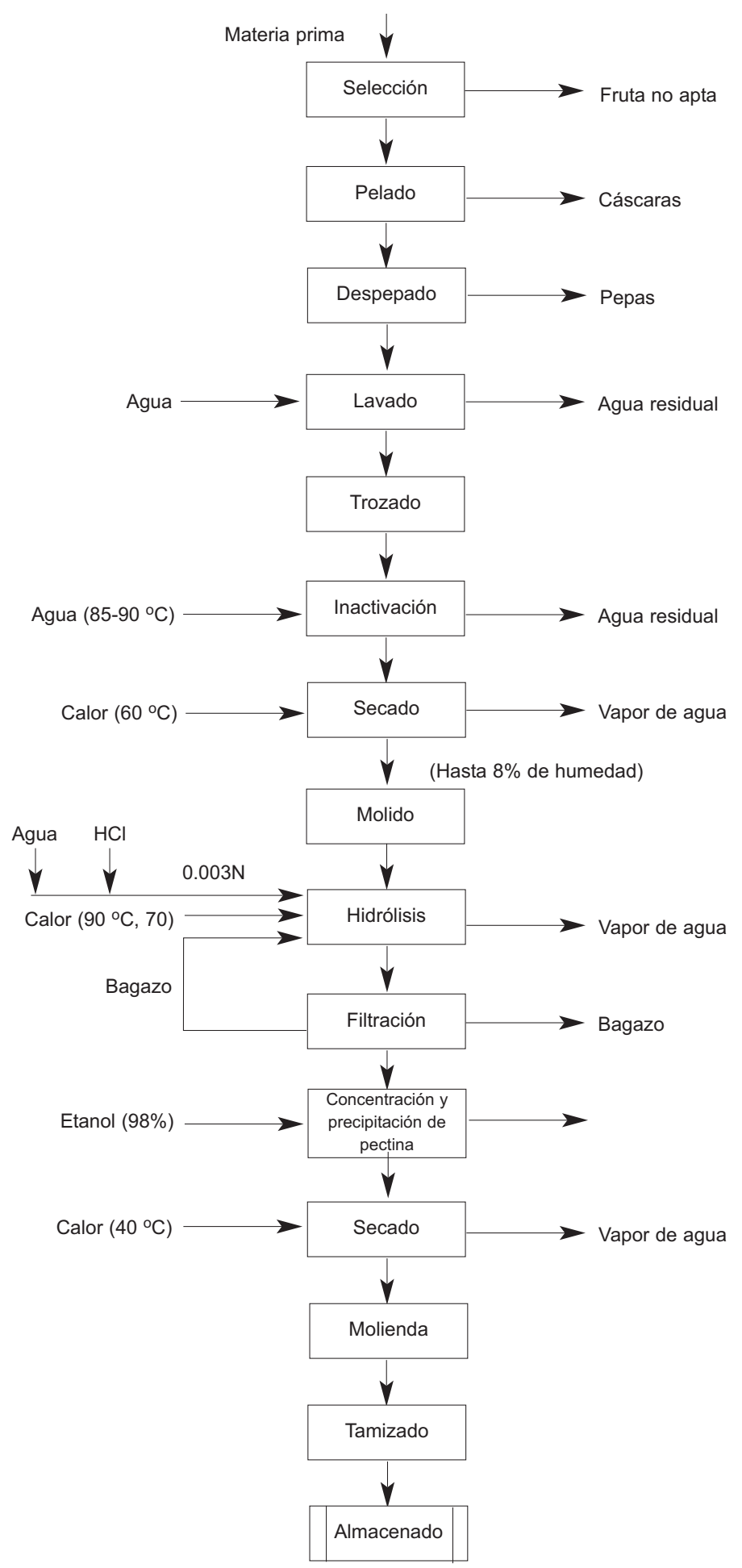




\subsection{Caracterización de la pectina}

La calidad de la pectina se determinó por sus propiedades físicoquímicas sobre la base del porcentaje de metoxilos (Carbonell, Costell y Durán, 1990:1-9), grado de metoxilación (Gee, Mccomb, McCready, 1958;23,72-75), contenido de ácido anhidro galacturónico (\% AAG) (Gierselmer, 1997: 171-185), humedad (AOAC, 1983), cenizas totales (AOAC, 1984), viscosidad relativa, viscosidad intrínseca, peso molecular (Gierselmer, 1997: 171-185). Los grupos funcionales presentes en las pectinas de la pulpa del níspero de la sierra y en el mesocarpo de la granadilla se determinaron mediante el espectrofotómetro infrarrojo con transformada de Fourier (FTIR), por el método de transmisión (muestra laminada), leída directamente (Manrique, Lajolo, 2002: 99107).

\section{RESULTADOS Y DISCUSIÓN}

En la tabla 1 se muestra el porcentaje de pectato de calcio determinado en 14 frutos y en un tubérculo andino que se cultivan en nuestro país. Se observa que el mayor porcentaje de pectato de calcio se encuentra en la pulpa del níspero de la sierra y en el mesocarpio de la granadilla, por lo que ambos frutos se seleccionaron para la extracción y caracterización de la pectina.

En la tabla 2 se puede observar que los porcentajes de carbohidratos $(6,05 \%)$, grasas $(0,61 \%)$ y cenizas $(1,96 \%)$ del mesocarpio de la granadilla se encuentran en menor cantidad que en la pulpa del níspero de la sierra. Los mayores porcentajes de humedad $(87,74 \%)$ y de proteínas $(0,54 \%)$ se encuentran en el mesocarpio de la granadilla que en la pulpa del níspero de la sierra.

La extracción de pectina se realizó con $\mathrm{HCl} 0,003 \mathrm{~N}$ a $\mathrm{pH} 2,5$, a la temperatura de $90^{\circ} \mathrm{C}$ y por un tiempo de extracción de 75 minutos, obteniéndose un rendimiento máximo de pectina de $23,85 \%$ para la pulpa del níspero de la sierra y de $21,60 \%$ para el mesocarpo de la granadilla, semejante a la pectina obtenida de los frutos cítricos (20-35\%). 


\section{Tabla 1}

Porcentaje de pectato de calcio total en frutos amazónicos, andinos y costeños

\begin{tabular}{lc}
\hline Fruto & Pectato de calcio (\%) \\
\hline Níspero de la sierra (Nespilus germánica) & 8,40 \\
Mesocarpio de la granadilla (Pasiflora ligularis) & 8,00 \\
Lúcuma (Pouteria lucuma) & 7,12 \\
Carambola (Averrhoa carambola) & 6,40 \\
Guayaba (Psidium guajava) & 4,95 \\
Cáscara de maracuyá (Pasiflora edulis) & 4,90 \\
Ciruelo del fraile (Bunchosia armeniaca) & 4,60 \\
Tomate de árbol (Cyphomandra betacea) & 4,34 \\
Chirimoya (Annona cherimola Mill) & 2,05 \\
Cocona (Solanum sessiliflorum) & 1,38 \\
Cáscara de tuna (Opuntia ficus indica) & 0,99 \\
Jugo de granadilla (Pasiflora ligularis) & 0,54 \\
Jugo de tumbo (Mollísima H:B:K, Bailey) & 0,50 \\
Aguaymanto (Phisalis peruviana) & 0,12 \\
Jugo de maracuyá (Pasiflora edulis) & 0,09 \\
Yacón (Smallanthus sonchifolius) & 0,05 \\
Jugo de tuna (Opuntia ficus indica) & 0,02 \\
Camu-camu (Myrciaria dubia) & Trazas \\
\hline
\end{tabular}

Tabla 2

Análisis proximal de la pulpa del níspero de la sierra y del mesocarpio de la granadilla

\begin{tabular}{lccccc}
\hline Fruto & $\begin{array}{c}\text { Humedad } \\
(\%)\end{array}$ & $\begin{array}{c}\text { Cenizas } \\
(\%)\end{array}$ & $\begin{array}{c}\text { Proteínas } \\
(\%) \\
(\mathbf{N} * \mathbf{5}, 71)\end{array}$ & $\begin{array}{c}\text { Grasas } \\
(\%)\end{array}$ & $\begin{array}{c}\text { Carbohidratos } \\
(\%)\end{array}$ \\
\hline $\begin{array}{l}\text { Pulpa del níspero } \\
\text { de la sierra }\end{array}$ & 68,04 & 3,89 & 0,51 & 0,78 & 17,66 \\
$\begin{array}{l}\text { Mesocarpio } \\
\text { de la granadilla }\end{array}$ & 87,74 & 1,96 & 0,54 & 0,61 & 6,05 \\
\hline
\end{tabular}


El contenido de humedad y cenizas se reporta en la tabla 3. Se observa que la pectina extraída de la pulpa del níspero de la sierra, tiene el más alto contenido de agua (17,80\%), comparado con el de la pectina comercial (Merck) (10,81\%). En cuanto al contenido de cenizas, se aprecia que están cercanos al 6,07\% reportado por Kar y Arslan (1999a: 285-291). El contenido de cenizas afecta la habilidad de la pectina de gelificarse (Miyamoto y Chang, 1992: 1439-1443).

Tabla 3

Análisis de humedad y cenizas de las pectinas extraídas de la pulpa del níspero de la sierra y del mesocarpio de la granadilla

\begin{tabular}{lccc}
\hline Componente & $\begin{array}{c}\text { Pulpa del níspero } \\
\text { de la sierra }\end{array}$ & $\begin{array}{c}\text { Mesocarpio } \\
\text { de la granadilla }\end{array}$ & Pectina estándar \\
\hline Humedad (\%) & 17,80 & 17,50 & $10,81^{*}$ \\
Cenizas (\%) & 3,47 & 4,95 & $6,07^{* *}$ \\
\hline
\end{tabular}

* Pectina comercial, Merck.

** Reportado por Kar y Arslan (1999a: 285-291).

En las tablas 4 y 5 se muestran los parámetros que determinan la calidad de la pectina. El contenido de metoxilos obtenido es de $14,55 \%$ para la pectina de la pulpa del níspero de la sierra y de $14,71 \%$ para la pectina del mesocarpio de la granadilla, observándose entonces que las pectinas extraídas son de alto metoxilo, ya que presentan valores por encima de las especificaciones internacionales (6,7\%).

El alto porcentaje de ácido galacturónico (AAG) y el bajo porcentaje de cenizas en la pectina son dos de los criterios que evalúan la pureza de las pectinas. El contenido de cenizas afecta la habilidad de la pectina a gelificarse (Miyamoto y Chang, 1992: 1439-1443). Desde que el ácido anhidro galacturónico (AAG) es la unidad fundamental de la estructura de las pectinas, su cuantificación es importante para determinar el contenido de pectina en el producto. Los porcentajes de AAG de 87,93 para la pectina de la pulpa del níspero de la sierra y de 87,75 para la pectina del mesocarpio de la granadilla indican una alta concentración del AAG y se encuentran dentro de las especificaciones internacionales. 
Tabla 4

Características químicas de las pectinas extraídas de la pulpa del níspero de la sierra y del mesocarpio de la granadilla

\begin{tabular}{|c|c|c|c|}
\hline $\begin{array}{l}\text { Características } \\
\text { químicas }\end{array}$ & $\begin{array}{c}\text { Pulpa del níspero } \\
\text { de la sierra }\end{array}$ & $\begin{array}{c}\text { Mesocarpio } \\
\text { de la granadilla }\end{array}$ & $\begin{array}{l}\text { Especificaciones } \\
\text { internacionales }\end{array}$ \\
\hline Metoxilos (\%) & 14,55 & 14,40 & mín. 6,70\% (USP) \\
\hline $\begin{array}{l}\text { Ácido anhidro } \\
\text { galacturónico } \\
(\mathrm{AAG})(\%)\end{array}$ & 87,93 & 85,99 & $\begin{array}{c}\text { mín. 74\% (USP) } \\
\text { mín. 65\% (UE, } \\
\text { FAO/WHO, FDA/FCC) }\end{array}$ \\
\hline $\begin{array}{l}\text { Grado de } \\
\text { metoxilación (\%) }\end{array}$ & 89,15 & 88,24 & $\geq 50 \%$ \\
\hline $\begin{array}{l}\text { Grado de } \\
\text { esterificación (\%) }\end{array}$ & 86,24 & 88,79 & $81,50 \%$ \\
\hline Tipo de pectina & $\begin{array}{c}\text { Alto metoxilo (HM) } \\
\text { rapid set } \\
\text { (gelificación } \\
\text { ultrarrápida) }\end{array}$ & $\begin{array}{l}\text { Alto metoxilo (HM) } \\
\text { rapid set } \\
\text { (gelificación } \\
\text { ultrarrápida) }\end{array}$ & \\
\hline UE & Unión Europea & & \\
\hline $\mathrm{FAO} / \mathrm{WHO}=$ & Food \& Agriculture Organ & zation/World Health Org. & \\
\hline FCC & Food Chemical Codex & & \\
\hline FDA & Food and Drug Administr & tion & \\
\hline USP & Farmacopea de Estados & Inidos & \\
\hline
\end{tabular}

Las propiedades fisicoquímicas de las pectinas relacionadas con la función que desarrollan como fibra y como agente espesante en los alimentos, están determinadas, en gran medida, por el grado de metoxilación de los grupos ácidocarboxílicos (Barford, Magidman, Philips y Fishmnan, 1986: 2576-2578). El grado de metoxilación en las muestras analizadas se encontró por encima del 50\% (Bernhard, Menzies y Blamey, 2004: 375-378), lo cual confirma que las pectinas de la pulpa del níspero de la sierra y del mesocarpio de la granadilla son de alto metoxilo y de gelificación ultrarrápida (rapid set) (Kar y Arslan, 1999b: 285-291). Por lo tanto, las pectinas estudiadas pueden ser empleadas en el procesamiento de mermeladas, confituras y jaleas, debido a que la habilidad de la pectina a gelificarse depende mayormente de su grado de metilación. Los mecanismos de la gelificación de 
las pectinas dependen del grado de metoxilación. Las pectinas de alto metoxilo se gelifican debido a interacciones hidrofóbicas y a los puentes de hidrógeno entre las moléculas de la pectina, a bajo $\mathrm{pH}(\approx 3) \mathrm{y}$ con alto contenido de azúcar (Oakenfull, 1991: 87-108).

En contraste, las pectinas de bajo metoxilo forman geles en presencia de calcio $\mathrm{u}$ otros cationes divalentes en un amplio rango de $\mathrm{pH}$, con o sin azúcar. Debido a su bajo contenido de azúcar, las pectinas de bajo metoxilo tienen muchas aplicaciones en alimentos bajos en calorías y en alimentos dietéticos (May, 1990: 79-99).

Las características químicas de las pectinas que influyen en la fuerza del gel son el grado de esterificación y el peso molecular; por lo tanto, el grado de esterificación es un factor clave para determinar la conformación y las propiedades reológicas de las pectinas (Hwang, Roshdy, Kontominas, Kokini, 1992: 1180-1184). El grado de esterificación también está relacionado con la formación del tipo de gel. A mayor grado de esterificación mayores serán las interacciones hidrofóbicas, por lo que el gel será más fuerte. Además, un alto grado de esterificación conlleva una mayor temperatura de gelificación, por eso se llaman pectinas ultrarrápidas. Las pectinas estudiadas tienen un alto grado de esterificación: $86,24 \%$ y $88,79 \%$, respectivamente, comparado con el 81,50\% de la pectina comercial (Sharma, Liptay, Le Moguer, 1998: 543-547).

La habilidad de la pectina a gelificarse también depende de su solubilidad, viscosidad y de su peso molecular (Rao, 1993: 66-67). La viscosidad no solo depende de la concentración del polímero, sino también del peso molecular. Cuanto más alto es el peso molecular mayor es su viscosidad, por consiguiente mayor es su grado de gelificación. La molécula de pectina puede contener 100 mil unidades o más, correspondiente al peso molecular, lo que depende de la materia prima empleada.

El conocimiento de la viscosidad intrínseca ayuda en la determinación del peso molecular y consiste en la capacidad de la molécula del polímero a incrementar la viscosidad (Kar y Arslan, 1999: 277-284). Las magnitudes del grado de gelificación, viscosidad relativa, viscosidad intrínseca y peso molecular obtenidos para las pectinas estudiadas se indican en la tabla 5. 
Tabla 5

Características físicas de las pectinas extraídas de la pulpa del níspero de la sierra y del mesocarpio de la granadilla

\begin{tabular}{lccc}
\hline Características físicas & Níspero de la sierra & $\begin{array}{c}\text { Mesocarpio de la } \\
\text { granadilla }\end{array}$ & $\begin{array}{c}\text { Especificaciones } \\
\text { internacionales }\end{array}$ \\
\hline Grado de gelificación & 200 & 260 & $0-300$ \\
Viscosidad relativa & 1,49 & 1,85 & $1.1-2.1$ \\
Viscosidad intrínseca & 4,25 & 6,5 & $1,0-9,0$ \\
Peso molecular & 10183,5 & 16366,96 & $100,000-200,000$ \\
\hline
\end{tabular}

Los espectros infrarrojos (IR) de las pectinas obtenidas del proceso de extracción ácida del mesocarpio de la granadilla y de la pulpa del níspero de la sierra se indican en las figuras 4 y 5 , respectivamente.

Figura 4

Espectro IR de la pectina del mesocarpio de la granadilla

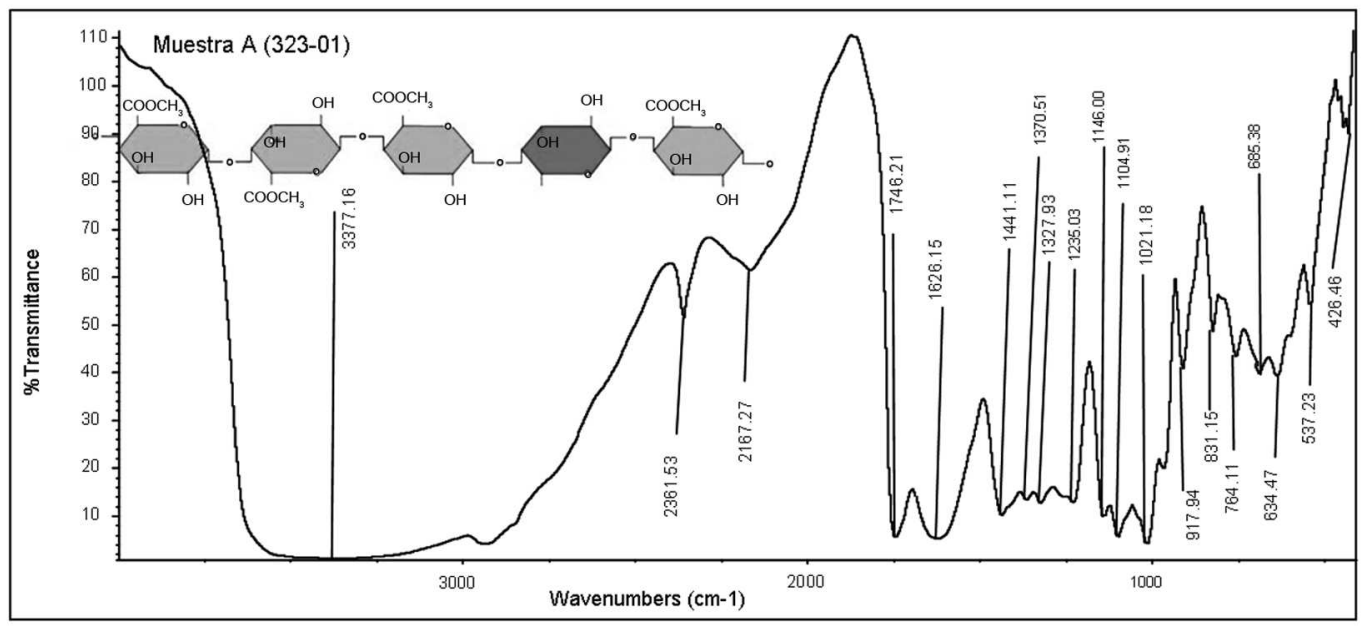




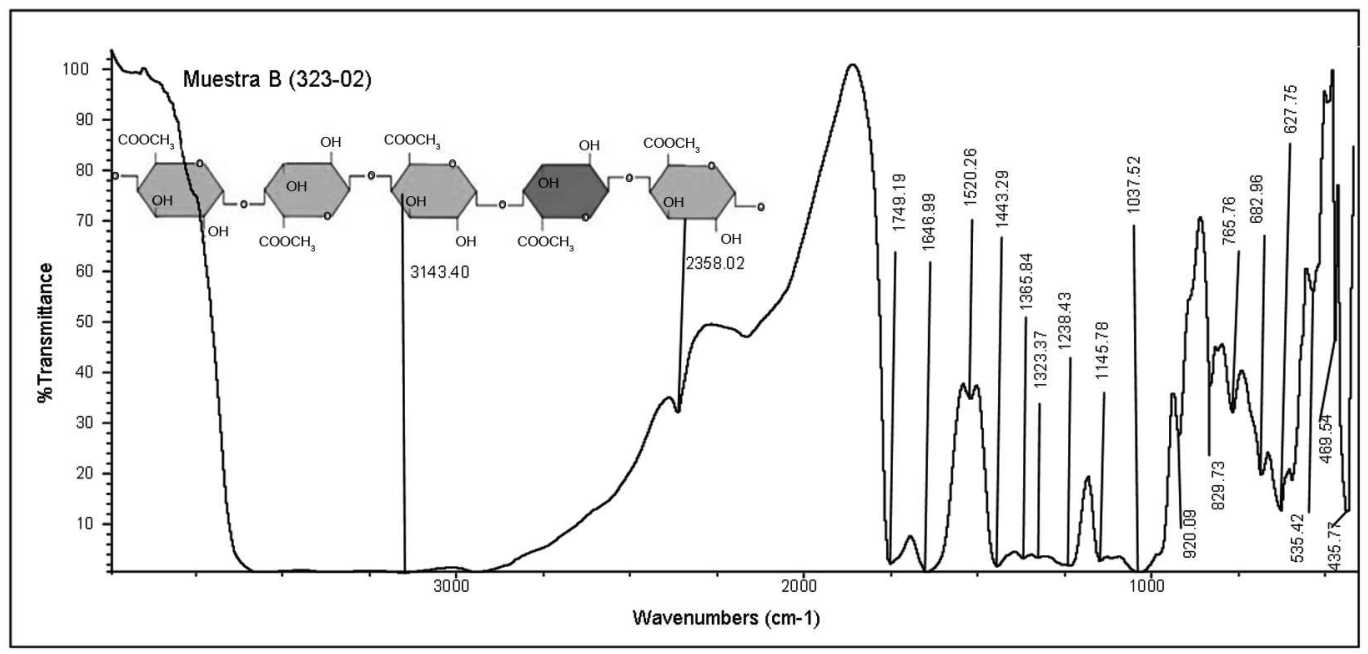

En ambos espectros se observa un pico ancho de 3143,40 y 3377,16 $\mathrm{cm}^{-1}$ debido a la vibraciones de tensión del $\mathrm{O}-\mathrm{H}$, lo cual indica que existen muchos grupos $\mathrm{O}-\mathrm{H}$ en la estructura de la pectina. La banda de $2930 \mathrm{~cm}^{-1}$ corresponde a la tensión del $\mathrm{C}-\mathrm{H}$ de los grupos $\mathrm{CH}_{2}$.

Las bandas de particular importancia para la determinación del grado de esterificación son aquellas que aparecen alrededor de $1630 \mathrm{~cm}^{-1}$ y $1750 \mathrm{~cm}^{-1}$ y son indicadoras de grupos carboxilos libres y esterificados, los cuales son útiles para determinar el grado de esterificación y para la identificación de pectinas de alto y bajo metoxilo (Manrique, 2002: 99-107). Estos espectros presentan características similares; ya que mostraron un alargamiento pronunciado entre $1626,15-1646,99 \mathrm{~cm}^{-1}$ que corresponde a la banda de vibración de tensión simétrica del grupo $\mathrm{COO}^{-}$, mientras que las bandas que aparecen entre $1746,2 \mathrm{~cm}^{-1}-1749,19 \mathrm{~cm}^{-1}$ corresponden a los grupos carbonilos de los grupos $\mathrm{COOH}$ y de los grupos acetilos $\left(\mathrm{COOCH}_{3}\right)$ de la pectina. La presencia de ambas bandas confirma el alto grado de esterificación y la presencia de pectina de alto metoxilo en el mesocarpio de la granadilla y en la pulpa del níspero de la sierra, respectivamente. 
Los picos a $1370,51-1441,11 \mathrm{~cm}^{-1}$ y $1365,84-1443,29 \mathrm{~cm}^{-1}$ corresponden a la banda de vibración de tensión del C-O-H. A 1327,93 y $1365,84 \mathrm{~cm}^{-1}$, existe una banda de vibración de tensión del C-O. Los picos a 1235,03 y $1238,43 \mathrm{~cm}^{-1}$ son la banda de vibración de tensión asimétrica del $\mathrm{C}-\mathrm{O}-\mathrm{C}$, e indican la abundancia de los grupos metoxilos $\left(-\mathrm{O}-\mathrm{CH}_{3}\right)$. El pico fuerte a $1021,18 \mathrm{~cm}^{-1}$ y $1037,52 \mathrm{~cm}^{-1}$ indican la banda de vibración de tensión del grupo simétrico $\mathrm{C}-\mathrm{O}-\mathrm{C}$ que confirma también el alto grado de esterificación y la presencia de pectina de alto metoxilo en las pectinas estudiadas.

\section{CONCLUSIONES}

- Las características fisicoquímicas y el análisis espectrotométrico infrarrojo confirman que las pectinas obtenidas son de alto metoxilo, de alta pureza y de buena calidad.

- El alto grado de esterificación, peso molecular elevado, confirman la fuerza del gel, por lo que las pectinas obtenidas pueden ser empleadas en la manufactura de mermeladas, jaleas, confites, yogures de frutas, en bebidas de bajas calorías, alimentos probióticos, en productos farmacéuticos y dietéticos, ya que tienen un efecto positivo en la reducción de colesterol en la sangre.

- Esta investigación contribuye a incrementar el valor agregado de estas frutas y a la creación de nuevos productos para el mercado interno y la agroexportación.

\section{BIBLIOGRAFÍA}

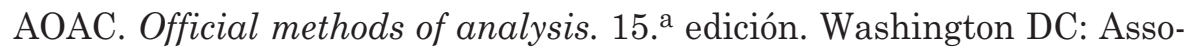
ciation of Official Analytical Chemists, 1990.

- AOAC. Official methods of analysis. 14. ${ }^{\text {a }}$ edición. Washington DC: Association of Official Analytical Chemists, 1984.

—. Official methods of analysis. $13 .^{\text {a }}$ edición. Washington DC: Association of Official Analytical Chemists, 1983.

Barford, R. A.; Magidman, P.; Philips, J. G. y M. L. Fishmnan. "Estimation of degree of methylation of pectin by pyrolysis-gas chromatography". Analytical Chemistry 58, 1986. 
Bernhard, W. J.; Menzies, N. W. y F. P. C. Blamey. "Alkali hydroxideinduce gelation of pectin". Food Hydrocolloids 18, 2004.

Carbonell, E.; Costell, E. y L. Durán. "Determinación del contenido de pectinas en productos vegetales". Rev. Agroquím. Tecnol. Alim. 30, 1990.

Doco T.; Williams, P.; Vidal, S. y P. Pellerin. "Rhamnogalacturonan II, a dominant polysaccharide in juices produced by enzymic liquefaction of fruits and vegetables”. Carbohydr. Res. 297, 1997.

Gee, M.; Mccomb, E. A. y R. M. McCready. "A method for the characterization in some fruit and sugar-beet marcs". Food Research 23, 1958.

Gierselmer, K. "Pectin and pectin enzymes in fruit". Vegetables techno$\log y$ 118, 1997.

Heitman, D. W.; Hardman, W. E. e I. L. Cameron. "Dietary supplementation with pectin and guar gum on 1,2-dimetilhidrazine-induced colon carcinogenesis in rats". Carcinogenesis 13, 1992.

Hwang, J. K.; Roshdy, T. H.; Kontominas, M. y J. L. Kokini. "Comparison of dialysis and metal precipitation effects on apple pectins". Journal of Food Science 57, 1992.

Kar, F. y N. Arslan. "Characterization of orange peel pectin and effect of sugars, L-ascorbic acid, ammonium persulfate, salts on viscosity of orange peel pectin solutions". Carbohydrate Polymers 40, 1999a.

—. "Effect of temperature and concentration of viscosity of orange peel pectin solutions and intrinsic viscosity-molecular weight relationship". Carbohydrate Polymers 40, 1999b.

Manrique, G. D. y F. M. Lajolo (2002). "FT-IR spectroscopy as a tool for measuring degree of methyl esterification in pectins isolated from ripening papaya fruit". Postharvest Biology and Technology 25, 2002.

May, D. C. "Industrial pectins: sourdes, production and applications". Carbohydrate Polymers. 12, 1990.

Miyamoto, A. y K. C. Chang. "Extraction and physicochemical characterization of pectin from sunflower head residues". Journal of Food Science 57, 1992. 
Nangia-Makker. P.; Hogan, V.; Honjo, Y.; Baccarini, S.; Tait, L.; Bresalier, R. y A. Raz. "Inhibition of human cancer cell growth metastasis in nude mice by oral intake of modified citrus pectin". Journal of National Cancer Institute 94, 2002.

Nwanekesi, E.; Alawuba, O y C. Mkpolulu. "Characterization of pectic substances from select tropical fruits". J. Sci. Technol. 31, 1994.

Oakenfull, D. G. "The chemistry of high-metoxyl pectin gelation", en Walter, R. H. The chemistry and technology of pectin. Nueva York: Academic Press, Inc., 1991.

O’Neil, M.; Albersheim, P. y A. Darvill. "The pectic polysaccharides of primary cell walls", en Dey, D. M. (ed.). Methods in Plant Biochemistry, Vol. 2. Londres: Academic Press, 1990.

Pellerin, P.; O’Neil, M.; Pierre C.; Cabanis, M. T.; Darvill, A. G.; Albersheim, P. y M. Moutormet. "Lead complexation in wines with the dimmers of the grape pectic polysaccharide rhamnogalacturonan II". J. Int. Sci. Vigne et. Vin. 31, 1997.

Pellerin, P. y M. O'Neil. "The interaction of the pectic polysaccharide rhamnogalacturonan II with heavy metals and lantanides in wine and fruit juices". Analysis 26, 1998.

Pienta, K. J.; Naik, H.; Akhtar, A.; Yamazaki, K.; Replogle, T. S.; Lehr, J.; Donat, T. L.; Tait, L.; Hogan, V. y A. Raz. "Inhibition of spontaneous metastasis in a rat prostate cancer model by oral administration of modified citrus pectin". Journal of National Cancer Institute 87, 1995.

Platt. D. y A. Raz. "Modulation of the lung colonization of B16-F1 melanoma cells by citrus pectin". Journal of the National Cancer Institute 84, 1992.

Ridley, B. L.; O’Neill, M. A. y D. Mohnen. "Pectins: structure, biosynthesis and oligalacturonide-related signalling". Phytochemistry 57, 2001.

Sharma, S. K.; Liptay, A. y M. Le Maguer. "Molecular characterization, physico-chemical and functional properties of tomato fruit pectin". Food Research International, Vol. 30, núm. 7, 1998.

Shin, K. S.; Kihyohara, H.; Matsumoto, T. y H. Yamada. "Rhamnogalacturonan II dimers cross-linked by borate diesters from the leaves 
of Panax ginseng C.A. Meyer are responsible for expression of their IL-6 production enhancing activities". Carbohydr. Res. 307, 1998.

Srinrangarajan, A. y A. Shrikhande. "Technical note: Comparative aspects of pectin extracted from the peels of different varietes of mango". J. Food Technol. 14, 1979.

Szpubar, J.; Pellerin, P.; Makov, A.; Doco, T.; Willianm, P. y K. Lobinski. "Speciation of metal carbohydrate complex in fruit and vegetable samples by size exclusion HPLC-ICP-MS". J. and Atomic spectrum. 14, 1999.

Tahiri, M.; Pellerin, P.; Tressol, J. C.; Doco, T.; Pepin, D.; Rayssignior, J. y C. Coudray. "The rhamnogalacturonan II dimmer decreases intestinal absorption and tissue accumulation of lead in rats". $J$. Nutr. 130, 2000.

Willats, W. G. T.; Knox, I. P. y M. J. Dalgaard. "Pectin: new insights into and old polymer are starting to gel". J.Sci. Technol. 17, 2006.

Yamada, H. Contributions of pectins on health care. Pectins and pectinases: proceedings of an international symposium. Wageningen, Países Bajos, 3-7 de diciembre de1995. Editado por Visser J, Voragen AGJ. Amsterdam: Elsevier, 1996. 


\section{GLOSARIO}

Ácido galacturónico: monosacárido correspondiente a la forma oxidada de la D-galactosa. Es el principal componente de las pectinas.

Biopolímero: Especie química de alto peso molecular, forma parte de las paredes celulares de las plantas

Esterificación: proceso por el cual se sintetiza un éster. Un éster es un compuesto derivado formalmente de la reacción química entre un oxácido y un alcohol.

FT-IR: espectroscopía infrarroja con transformada de Fourier.

Hidrólisis: reacción química del agua con una sustancia que produce un desplazamiento del equilibrio de disociación del agua y como consecuencia se modifica el valor del $\mathrm{pH}$.

Mesocarpio: capa media de las tres capas que forman el pericarpio de los frutos; por ejemplo, la parte carnosa del melocotón.

Metoxilo: un grupo funcional consistente en un grupo metilo unido a un oxígeno, con fórmula: $-\mathrm{O}-\mathrm{CH}_{3}$.

Monosacáridos: azúcares simples, glúcidos más sencillos que contienen de tres a seis átomos de carbono. Su fórmula empírica es $\left(\mathrm{CH}_{2} \mathrm{O}\right)_{n}$ donde $n \geq 3$.

Oligosacáridos: polímeros de monosacáridos con un número de unidades monoméricas entre 2 y 10.

Pectatos: sales de los ácidos pécticos (ácidos pectínicos desmetoxilados); sus propiedades y usos son comparables a los de las pectinas.

Pectinatos: sales de los ácidos pectínicos (ácidos poligalacturónicos parcialmente metoxilados).

Polisacáridos: biomoléculas formadas por la unión de una gran cantidad de monosacáridos y se encuentran en la pared celular de las plantas.

Viscosidad intrínseca: parámetro que se emplea como indicador de la longitud promedio y peso molecular de las cadenas regulares de unidades repetitivas de una macromolécula.

Viscosidad relativa: viscosidad de una muestra líquida con respecto a la viscosidad del agua. 